\title{
НАЦИОНАЛЬНО-КУЛЬТУРНЫЕ ОСОБЕННОСТИ МЕТАФОРИЧЕСКОГО ПРЕДСТАВЛЕНИЯ ТЕМАТИЧЕСКОЙ ГРУППЫ «ПРОДУКТЫ ПИТАНИЯ» В РУССКОЯЗЫЧНЫХ И КИТАЙСКОЯЗЫЧНЫХ РЕКЛАМНЫХ ТЕКСТАХ
}

\section{CULTURE FEATURES \\ OF THE METAPHORICAL PRESENTATION \\ OF THE THEMATIC GROUP «FOOD» \\ IN RUSSIAN AND CHINA LANGUAGE ADVERTISTING TEXTS}

Zhu Xiangyu

Summary: The article is devoted to the study of metaphors of the thematic group «food» in the Russian and Chinese linguistic picture of the world on the material of advertising texts. The main goal of our research is to analyze the metaphorical representation of the thematic group «Food» in the Russian and Chinese linguistic picture of the world on the basis of advertising texts. Scientific originality of the paper lies in the fact that we analyse the thematic group «Food» in the Russian advertising texts from the position of the carrier of the Chinese linguistic culture. The paper is based on the classical classifications of metaphors and metaphorical models. As a result, we summarized the differences between Chinese and Russian cultural characteristics from the analysis of the metaphor of advertising texts.

Keywords: thematic group "food»; linguistic picture of the world; metaphorical model; national and cultural characteristics; advertising texts.

\section{Введение}

И сследование метафоры в современной лингвистике неизбежно приводит к необходимости изучения той роли, которую играет метафора в формировании и функционировании языковой картины мира того или иного этноса. Актуальность настоящего исследования определяется тем, что, во-первых, тематическая группа «Продукты питания» как единица языковой картины мира является одним из важнейших факторов жизнедеятельности человека и находит свое воплощение в языковой семантике лексических единиц и в коммуникативной деятельности носителей русского языка и русской культуры. Во-вторых, в предыдущих исследованиях отсутствуют работы, посвященные метафорическому представлению данной тематической группы в рекламных текстах с позиции носителя другой лингвокультуры (в нашем случае - китайской). В-третьих, при
Аспирант, Пекинский университет иностранных языков

(2. Пекин, КНР)

zhuxiangyu050@mail.ru

Аннотация: Статья посвящена исследованию метафор тематической группы «продукты питания» на материале русскоязычных и китайскоязычных рекламных текстов. Цель заключается в выявлении национально-культурных особенностей метафорического представления тематической группы «Продукты питания» в рекламных текстах. Научная новизна обнаруживается в системном анализе метафорического представления тематической группы «Продукты питания» в рекламных текстах. В результате определяются различия и сходства национально-культурных особенностей метафорического представления тематической группы «Продукты питания» в русскоязычных и китайскоязычных рекламных текстах.

Ключевые слова: тематическая группа «Продукты питания»; языковая картина мира; метафорическая модель; национально-культурные особенности; рекламные тексты.

понимании метафорического представления тематической группы «Продукты питания» в русскоязычных рекламных текстах существуют барьеры, обусловленные языковой системой и национальной культурой, что оказывает большое влияние на эффект коммуникации.

Для достижения поставленной цели представляется необходимым решить следующие задачи:

1. создать типологию метафорических групп тематической группы «Продукты питания» в русскоязычном и китайскоязычном рекламном тексте;

2. провести сопоставительный анализ метафорической модели тематической группы «Продукты питания» в русскоязычном и китайскоязычном рекламном тексте;

3. выявить национально-культурные особенности формирования метафорического представления тематической группы «Продукты питания» в рус- 
ском языке (с позиции носителя китайской лингвокультуры).

Теоретической базой исследования послужило содержание работ, освещающих проблемы теории метафоры, языковой картины мира и рекламного дискурса: Г.С. Баранов [3], Дж. Лакофф, М. Джонсон [8], К. М. Шилихина [14] и другие.

Практическая значимость работы состоит в том, что ее результаты могут быть использованы в преподавании курсов по лексикологии и стилистике русского языка, в спецкурсах по теории текста и дискурса, в различных спецкурсах, посвященных рекламному дискурсу, а также в практике преподавания РКИ. Результаты такого описания могут быть полезны для дальнейшего изучения рекламного дискурса и метафорического представления тематической группы в русскоязычной и межкультурной коммуникации.

Материалом исследования послужили тексты наружной рекламы на биллбордах, тексты на флаерах и рекламных открытках, реклама в интернете, на радио и телевидении. При отборе был использован метод целенаправленной выборки.

\section{1. Тематическая группа «Продукты питания» как фактор организашии метафорической картины мира в рек^амных текстах}

Рекламные тексты охватывают почти все сферы человеческой деятельности. Бесспорным является тот факт, что в рекламе широко использованы образные слова, языковые выразительные средства или игровая коллизия, с помощью которых у создателей рекламных текстов получается достичь нужной эффективности и яркости. Таким образом, в настоящее время реклама составляет особую сферу для исследования языковых средств. Рекламный текст воссоздает свой вариант мира, который не повторяет характеристики мира реального, а усиливает их. Значимость каждого рекламируемого объекта в этом символическом мире утрированно возрастает. Если речь идет о чае, то именно чай оказывается способным решить проблемы социального, а не физического толка. Реклама повествует об объектах желания, поэтому она и обладает для нас определенной привлекательностью. Мир желаний - это и есть мир рекламы. По мнению Е.Б. Кургановой, одним из образных средств рекламы является метафора. Метафора, где бы она нам ни встретилась, всегда обогащает понимание человеческих действий и знаний [7, с. 48].

Не секрет, что реклама сегодня стала частью массовой культуры. Объектом воздействия рекламы является многомиллионная аудитория потенциальных потребителя товаров и услуг» [14]. Чтобы продвинуть товар на потребительском рынке, автор рекламы использует выразительное языковое средство, особенно метафору, при этом в рекламном дискурсе практически в чистом виде реализуется функция воздействия языка на адресата.

Речь идет о языковой метафоре, которая представляет собой не просто инструмент познания действительности, а также средство организации взаимодействия человеческой деятельности с внешним миром. Так Е.Б. Курганова считает, мир метафор - это мир нашего мышления, мир наших желаний, намерений, чувств: это вторая (не по порядку, а количественно) действительность [7, с. 50]. Изучением языка рекламы занимались Д.Э. Розенталь, Н.Н. Кохтев [11], были рассмотрены речевое воздействие и манипулирование в рекламе [9], реклама как интертекстуальный феномен [12], экспрессивные синтаксические конструкции в языке рекламы [1]. На сегодняшний день проведен ряд исследований, касающихся современной рекламной деятельности, приемов рекламы, языка рекламы и т.д. Одни исследователи рассматривают рекламу и язык рекламы, в основном, с точки зрения маркетинга и рекламной деятельности [11, с. 8], другие исследуют непосредственно сам язык рекламы [10], языковые и стилистические средства, использующиеся в нем, тексты рекламных сообщений и многие другие особенности современной рекламы.

Многие исследователи рассматривают метафору как источник имплицитной информации. Целый ряд эффективных механизмов коммуникативного воздействия основан на использовании имплицитной информации, то есть информации, которая представлена в сообщении в скрытом виде. Речь идет о таком способе передачи информации, при котором она в явном виде не выражается, но с необходимостью извлекается адресатом при интерпретации сообщения. Рассмотрению метафоры в рекламном тексте посвящены работы таких исследователей, как Е.Б. Курганова [7], Ю.В. Шатин [13], К.М. Шилихина [14], Х. Кафтанджиев [5].

Под влиянием общих процессов в языке происходят изменения, получившие название карнавализации. Впервые о карнавализации, точнее, о карнавальной культуре применительно к литературе, упоминал М.М. Бахтин [4]. Этот же термин позднее был использован применительно к «масс-медийным» текстам [6, с. 7].

Современная языковая ситуация характеризуется стремлением к использованию игры и игровых приемов практически во всех сферах словесности, что позволяет характеризовать ее следующим образом: «от карнавализации жизни к карнавализации языка» [6, с. 6]. В рекламе это выражается в использовании приемов языковой игры при создании рекламных текстов. Л.П. Амири связывает это со стремлением авторов текстов к усилению 
творческого начала [1, с. 8].

Наиболее полное описание и объяснение роли языковой метафоры в рекламном дискурсе содержится в статье К.М. Шилихиной «Использование метафоры в телевизионной рекламе» [14] и монографии Е.Б. Кургановой «Игровой аспект в современном рекламном тексте» [7].

Мы создали классификацию метафор тематической группы «Продукты питания» в русскоязычных и китайскоязычных рекламных текстах. Также мы использовали понятие «метафорическая модель» А.Н. Баранова в качестве важных параметров с целью провести сравнение метафорических представлений тематической группы «Продукты питания» в русской и китайской культуре.

\section{2. Метафоры в рек^амных текстах тематической группы «Продукты питания» в русской языковой картине мира}

Нами были выделены следующие типы метафор в рекламных текстах тематической группы «Продукты питания» в русской языковой картине мира:

1. Метафоры организма («Наши блинчики пекутся о здоровье!» (блинчики в ресторане Теремок);

2. Транспортные метафоры («Соль Валетек - Ваш путь к здоровью» (соль «Валетек»);

3. 3) Метафоры движения («Big Bon приходит во время еды» (лапша быстрого приготовления «Big Bon»);

4. Начально-конечные метафоры («Натуральный источник витаминов, который помогает Вам радоваться каждому новому дню» (Овощи, грибы и ягоды «Иитамин»);

5. Магические метафоры («Трапеза - волшебство на вашей кухне» (приправа «Трапеза»);

6. Сенсорные метафоры («Открой вкус лета» (чернослив Дары природы сушеный без косточек;

7. Абстрактные метафоры («Любовь с первой ложки» (лапша быстрого приготовления);

8. Метафоры, связанные с природными явлениями («Попробуй радугу! - Не кисни - на радуге зависни!» (жевательные конфеты с фруктовым вкусом «Skittles»;

9. Аква-метафоры («Молочные реки, фруктовые берега» (йогурты «Fruttis»);

10. Ландшафтные метафоры («Мед Горный - медовая долина» (мед Горный);

11. Масштабные метафоры («Планета витаминов. Сила жизни! Возьми домой витамины!» (Замороженные овощи «Планета витаминов»);

12. Метафоры, связанные с территориальным управлением («Страна чудес молочных» (молочные продукты «Чудо»);

13. Количественные метафоры («Наполни свою круж- ку пользой!» (ряженка, кефир, биокефир «Большая кружка»);

14. Физические метафоры («Питательная энергия (Батончик Mars 90-х г.);

15. Звуковые метафоры («Сладкая симфония от «Миредо» (ресторан «Миредо»);

16. Метафоры цвета («Настоящее черное золото» (семечки «Барин»);

17. Метафоры искусства («Вернитесь в русскую эпоху, попробуйте лучшие рецепты русской культуры» (Пельмени ресторана «На здоровье!»);

18. Оценочные метафоры («Кампомос - вкусная честная еда» (мясопродукты, мясокомбинат Кампомос);

19. Военные метафоры («Победитель среди оливковых» (оливковый майонез «Слобода»).

Распределение метафор по данным группам осуществлялось по ключевым словам. Отметим, что данная классификация не является абсолютной и может корректироваться. В некоторых случаях мы наблюдали сосуществование разных типов метафор в рекламных текстах, что осложняло работу по их классификации.

Самыми продуктивными метафорами в русских рекламных текстах являются сенсорные метафоры (особенно вкусовые метафоры), абстрактные метафоры (особенно метафоры с понятием «любовь»), метафоры, связанные с природными явлениями, оценочные метафоры (особенно метафоры с понятием «качество»), военные метафоры и антропоцентрические метафоры (широко используется олицетворение). Остальные классификации метафор являются менее продуктивными.

\section{3. Метафоры в рекламных текстах тематической группы «Продукты питания» в китайской языковой картине мира}

Мы выделили следующие группы метафор в китайских рекламных текстах, рекламирующих продукты питания (здесь и далее перевод выполнен автором статьи):

1. Метафоры организма (我们批发健康。- Мы продаем здоровье. (реклама из компании фруктов);

2. Метафоры питания (百鲜汇, 汇聚海洋百味营 养。 - Собрание питания от моря! (реклама из морепродуктов);

3. Транспортные метафоры (遇见最健康之路。Путь к здоровью. (реклама свинины);

4. Начально-конечные метафоры (伊利牛奶 一 美好 生活与生命的源泉。- Молоко «Или» - источник прекрасной жизни. (Молоко «Или»);

5. Сенсорные метафоры (多点健康, 多点滋味。(湾 仔码头水饺) - Больше вкуса здоровья! (реклама пельменей),

6. метафоры цвета (沁绿羊肉, 来自大草原的绿色问 候。 - Зеленый привет от большой степи. (реклама из баранины); 
7. Абстрактные метафоры (维维豆奶, 欢乐开怀。( 维维豆奶) - В объятьях радости и счастья (соевое молоко «Вэйвэй»);

8. Антропоцентрические метафоры (好面有精神 (康 师傅拉面)- Бодрая лапша! (реклама из лапши быстрого приготовления).

В китайскоязычной рекламной картине мира высокочастотными являются метафоры организма, сенсорные метафоры (особенно вкусовые метафоры, как и в русской рекламе) и антропоцентрические метафоры; менее частотным являются метафоры питания, транспортные метафоры, начально-конечные метафоры. По сравнению с русской рекламой, метафоры движения, магические метафоры, масштабные метафоры, количественные метафоры, физические метафоры, звуковые метафоры, военные метафоры, метафоры искусства в текстах китайской рекламы нами не обнаружены. Несмотря на то, что в китайской рекламной картине мира не наблюдается большое количество групп метафор, здесь возникают некоторые новые ключевые слова: слово «зеленый» в цветовых метафорах, понятие «семья» во вкусовых метафорах. Для современных китайцев «зеленые продукты» - это не только продукты зеленого цвета, но и здоровые продукты экологичного производства; современные китайцы обращают больше внимания на выбор продуктов питания, особенно стремятся к здоровым продуктам экологичного производства. В русской рекламе такие цветовые метафоры нами не обнаружены.

\section{4. Нашионально-культурные особенности метафорического представления тематической группы «Продукты питания» в русскоязычных и китайскоязычных рек^амных текстах}

В каждой национальной культуре тематическая группа «Продукты питания» эксплицирует соответствующие понятия, представления, образы, установки, приоритеты, стереотипы и оценки, отражающие специфику национального менталитета и мировосприятия, системы социокультурных отношений, традиций, обычаев и верований. Тематическая группа «Продукты питания» манифестирует как универсальные, так и национально-специфические аспекты, отражающие национально-культурные и исторические особенности. Здесь рассматриваются национально-культурные особенности метафорического представления тематической группы в русской и китайской рекламе.

На основе проанализированных нами примеров мы заметили, что в русской рекламной языковой культуре женских образов гораздо больше, чем в китайской, к примеру, «Путь к сердцу женщины» (макароны «Marco Aroni»), «Маленькая женская радость» (пастила и зефир в шоколаде «Шармэль»). Кроме этого, и широко используются такие «женские характеристики», как доброта, нежность, красота. Это объясняется тем, что русская женщина не только играет важную роль в русской кухне, но и занимает высокое место в обществе. Образ русской женщины в многих произведениях вобрал в себя все самые лучшие черты человеческих характеров, поэтому не удивительно, что образ женщины появляется и в рекламных текстах. В древнем Китае под влиянием феодальных взглядов женщина не заслуживала уважения со стороны общества, на ее работу и заслуги редко обращалось внимание. Несмотря на то, что в современном Китае эта ситуация изменилась, женские образы все-таки недостаточно используется в рекламном дискурсе.

В русской рекламе существует отдельная группа метафор - «Магические метафоры», которой почти нет в китайской рекламе. Магические метафоры связаны с понятием «магия». Употребительность метафор этой группы в русских рекламных текстах имеет связь с язычеством в Древней Руси, которое связано с расцветом магии и обращением к потусторонним силам. Русский человек обожествлял тех, кто хранил его род, дал ему все: солнце, еду, дом и т.п. Он всегда обожествлял то, что связано с добром, удачей, справедливостью, счастьем. Так же и в рекламном дискурсе. Такие магические метафоры создают соответствующую атмосферу вокруг предлагаемого товара или услуги, они особенно выражены в рекламных текстах, связанных с темой «Еда», так как еда - источник жизни и энергии, основа человеческой деятельности. Именно магические метафоры наиболее приближены к реализации одной из главных функций метафор: созданию символической реальности, при освоении которой человек нередко может пережить то, чего он еще по самым разным причинам не ощущал в обычной жизни. Как правило, магия лежит в основе религии, а в Китае с древних времен нет никакой доминирующей религии. Древние китайцы верили в силы своих предков, а современные китайцы предпочитают верить в свои силы, поэтому в китайском представлении магия не имеет особого смысла, поэтому магические метафоры редко появляются в китайской рекламной языковой картине мира.

Характерной особенностью языка в русском рекламном дискурсе является широкое использование метафорической военной лексики, так называемые «Военные метафоры». Военная метафорика в русском языке имеет глубокие исторические корни. Милитаристский характер дореволюционной России, реалии революций, войн, широкое освещение военных событий в СМИ, их отражение в художественной литературе обуславливает то, что многие специальные обозначения непрерывно активизируются в общелитературном употреблении. Процесс метафоризации военной лексики также эффективно происходит в языке рекламного дискурса. Активное метафорическое употребление военной лексики встречается в рекламных текстах, связанных с нашей темой 
«Продукты питания». К примеру, «Наша хлебная соломка - победитель программы «Контрольная закупка»» (Хлебная соломка «Manifesto» с солью), «Победитель среди оливковых» (оливковый майонез «Слобода»). А в китайской рекламе такие метафоры почти не существуют. Как мы уже отмечали выше, китайская культура развивается под влиянием учения Конфуция, который придерживался принципа «золотая середина» и мирной тактики. Тем более, китайский народ любит мир, гармонию, избегает конфликтов и неприятностей, не стремится создавать проблемы. Все это присуще китайцам, помнящим о правиле золотой середины. Вот почему в китайских рекламах отсутствуют военные метафоры.

Создавая рекламные тексты, авторы направлены на оптимальное воздействие на потребителя. В связи с этим рекламисты широко используют понятия или образы положительного характера, например, «здоровье», «качество», «любовь». Покупатели продуктов очень ценят такие слова, поэтому сразу обращают внимание на рекламируемые продукты. Это отражается и в русской, и в китайской рекламе. На наш взгляд, у русского народа и китайского народа существует немало общих ценностей. у обоих народов можно найти общее положительное отношение к труду, желание иметь счастье и здоровье, получать любовь от окружающих. И русские, и китайцы считают, что качественные продукты - гарантия здоровья, они улучшают жизнь, приносят человеку пользу, способствуют счастью. К примеру, в русской рекламе: Соль «Валетек» - Ваш путь к здоровью, в китайской рекламе: 伊利牛奶-幸福生活的源泉 - Молоко «Или» - источник прекрасной жизни. (Молоко «Или»), 品味甜蜜生 活，感受幸福味道- Наслаждайся сладкой жизнью, чувствуй вкус счастья! (торт «Хаолилай»).

Если речь идет об овощах или фруктах, русские рекламисты обращают внимание на констатацию их свежести, что проявляется в группе метафор, связанных с природой. Они есть и в русской, и в китайской рекламе: «Свежесть лета в каждой пачке» (Смесь овощей «Краски лета»), 田园青蔬，把自然包起来。- Внутри только вкус природы.

Продуктивна группа сенсорных метафор. В ходе нашего исследования мы заметили, что самым высокочастотной лексемой является «вкус». Вкус - один из самых важных параметров для измерения качества еды. В сфере продуктов питания вкусность чего-либо является субъективной оценкой, содержащей личностный параметр: горечь, сладость, кислота и др., например: «Вкус сладкой жизни» (шоколадные конфеты «Cote d'Or»), «Alpenliebe. Вкус сладких объятий.» (конфеты «Alpenliebe»), «Вкус переполняет» (шоколад «Milka M-joy») и др.

Такие «вкусовые» метафоры тоже часто появляются в китайских рекламах, что подтверждается следующими примерами:

1. 甜蜜时光，顶乐制造。 - Сладкое время создает торт ДинЛэ (Торт «Дин Лэ»);

2. 品味“双竹”面，感受大自然。- Вкус природы. (реклама лапши)

3. 一股浓香，一缕温暖。(南方黑芝麻糊) - Приятный вкус тепла. (реклама каши быстрого приготовления). При этом надо учитывать, в русской и китайской рекламе «вкусовые» метафоры, связанные с понятием «здоровье», «любовь», «природа», но в китайской языковой картине мира преобладают вкусовые метафоры с понятием «семья». Как мы отмечали выше, понятия «семья» и «родина» - важные элементы китайской языковой картины мира.

Когнитивная метафора - это механизм, позволяющий новую мысль представить через другую, известную мысль, иными словами, это способ думать об одной содержательной области посредством понятий о другой области, уже освоенной человеком.

Опираясь на когнитивную теорию метафор, принадлежащую Дж. Лакофф и М. Джонсону, и на проведенное исследование метафор тематической группы «Продукты питания» в рекламных текстах, мы выделили продуктивную метафорическую модель (далее М-модели): ЕДА - это ПОБЕДА. С помощью продуктов мы побеждаем голод, защищаем свой организм. Еда - самый важный источник человеческой энергии, именно еда обеспечивает нормальный и здоровой образ жизни, поэтому население любой страны с наибольшим вниманием относится к еде. В любой культурной среде еда особенно ценится. Человек с давних времен вынужден бороться с голодом и побеждать в этой борьбе: «Раздави голод!» (шоколадный батончик SNIKERS), «Наполеон - Триумф вкуса» (готовые и заказные торты и пирожные саратовской компании «Наполеон»), «Проглоти усталость и раздражение» (Реклама успокоительного средства). Приведем примеры победы еды, «Наша хлебная соломка - победитель программы «Контрольная закупка»» (Хлебная соломка «Manifesto» с солью), «Победы вкуса каждый день.» (майонез и приправы «Maggi»). Человек нуждается в защите, это также проявляется и в метафорических рекламах, к примеру, Dirol. Защищает Ваши Зубы. С Утра До Вечера» (жевательная резинка Dirol), Верный защитник вашей крепости» (кисломолочный продукт «Актимель»). В русской рекламной картине также реализуется такая мысль: ЕДА - это ДРУГ, ЕДА - это помощник, например, «Помощник Вашего Здоровья» (молочные продукты «Чудо-йогурт»), «Dirol - лучший друг ртов» (жевательная резинка Dirol).

В проанализированном нами материале представлены также структурные метафоры, к которым относятся такие метафорические модели, как: ЕДА - УДОВОЛЬ- 
СТВИЕ; ЕДА - НАСЛАЖДЕНИЕ. К примеру:

1. «Маленькие «Hershey's Kisses» - большое шоколадное удовольствие» (шоколадные конфеты «Hershey's Kisses»);

2. «Mars. Добавь удовольствия» (шоколад «Mars»);

3. «Большая порция вашего удовольствия. Для больших людей. У нас всегда Пятница! По пятницам!» (рестораны американской кухни Фрайдис «TGI Friday's»);

4. «Райское наслаждение» (шоколадный батончик с кокосовой начинкой «BOUNTY»).

Используя такие М-модели, авторы делают акцент на приятном вкусе, рекламируемых продуктов питания. Метафорические модели отличаются друг от друга метафорическими следствиями, т.е. теми свойствами обсуждаемой ситуации (или сущности), которые они профилируют в процессе метафоризации.» $[2$, с. 10]

Ориентационная метафора также проявляется в метафорических представлениях тематической группы «Продукты питания» в рекламе, к примеру:

1. «РотФронт. Мы подняли качество на новую высоту!» (шоколад «Ротфронт»);

2. «Gusto! Gusto! Подкрепи свой оптимизм!» (чипсы «GUSTO»);

3. «Сладости, приготовленные в кафе «Гараж», поднимают настроение» (сладости к кафе «Гараж»). В этих примеров ПОДНЯТОЕ НАСТРОЕНИЕ - это ВЕРХ, ПОДКРЕПЛЕННЫЙ ОПТИМИЗМ - тОЖе ВЕРХ.

Исходя из вышесказанного, мы пришли к следующему выводу: в русской языковой картине мира наиболее продуктивными когнитивными метафорическими моделями являются: ЕДА - это ПОБЕДА, ЕДА - это ДРУГ, ЕДА - это ЗАЩИТНИК, ЕДА - этО НАСЛАЖДЕНИЕ, ЕДА - эТО ЛЮБОВЬ, ЕДА - это МАГИЯ.

В китайской рекламной языковой картине мира мы тоже выделяем продуктивные М-модели. Прежде всего, это М-модель: ЕДА - это СПУТНИК, который всегда сопровождает нас в жизни. Здесь подчеркнута важность еды в человеческой деятельности. Например: 餐餐陪 着你。(李锦记榨菜) - Соленая капуста «Лизинь» сопровождает тебя во каждого приема еды (соленая капуста «Лизинь»).

Следующая продуктивная М-модель: ЕДА - это ВКУС СЕМЬИ. Например,

1. 月是故乡明，饼表思亲情! (中秋月饼) - Луна на родине особенно ясная, блины у нас - вкус родины. (реклама из лунных блинов);

2. 水塔陈醋，家的味道。- Вкус семьи! (реклама из уксуса);

3. 有家味, 生活永远好滋味。- Это вкус семьи, жизнь всегда радостная!(реклама из риса).
В китайской рекламе мы тоже выделяем М-модель: ЕДА - это ЛЮБОВЬ. Как и в русских рекламных текстах, слово «любовь» часто появляется в описании продуктов. К примеру:

1. 爱她，就请她吃哈根达斯。(哈根达斯冰淇淋)- Eë любишь, покупай ей Haagen-Dazs. Haagen-Dazs вкус любви! (мороженое «Haagen-Dazs»);

2. 水晶之恋, 一生不变。(喜之郎果冻) - Хрустальная любовь хранится на всю жизнь. (фруктовое желе);

3. 维维豆奶，欢乐开怀。(维维豆奶) - Соевое молоко - В объятьях радости и счастья (соевое молоко «Вэйвэй») и др.

Выделяется М-модель: ЕДА - НАСЛАЖДЕНИЕ, ЕДАУДОВОЛЬСТВИЕ. Например:

1. 酷酷的追求，甜甜的享受。(伊利雪糕) - Крутое стремление, сладкое наслаждение. (Мороженое «Или»);

2. 福气多多, 满意多多。(福满多方便面) - Внутри только вкус большого счастья и удовольствия (лапша быстрого приготовления «福满多»).

Приведенные выше примеры хорошо доказывают, что метафора вездесуща и проявляется не только в языке, но и в мышлении, и в деятельности людей. Наша обыденная понятийная система, в рамках которой мы мыслим и действуем, метафорична по самой своей сути [там же]. В нашем исследования можно предположить, что проанализированные нами метафоры наиболее полно отражают специфику метафорических представлений тематической группы «Продукты питания» в рекламных текстах и концептуализации современного мира, отраженного в русской и китайской языковой картине мира. С помощью метафор можно представить сухую и неинтересную информацию в очень выгодном свете. Тематическая группа «Продукты питания», являясь фрагментом языковой картины мира, эксплицирует соответствующие понятия, представления, образы, установки, приоритеты, стереотипы и оценки, отражающие специфику национального менталитета и мировосприятия, системы социокультурных отношений, традиций, обычаев и верований, характерных для русской и китайской культуры.

В результате решения поставленных задач мы пришли к следующим выводам:

1. самыми продуктивными метафорами в русских рекламных текстах являются сенсорные метафоры (особенно вкусовые метафоры), абстрактные метафоры (особенно метафоры с понятием «любовь»), метафоры, связанные с природными явлениями, оценочные метафоры (особенно метафоры с понятием «качество»), военные метафоры. В китайскоязычной рекламной картине мира высокочастотными являются метафоры организма, 
сенсорные метафоры (особенно вкусовые метафоры, как и в русской рекламе) и антропоцентрические метафоры;

2. в русской и китайской рекламе общими М-моделями являются: ЕДА - это ЛЮБОВЬ, ЕДА - это НАСЛАЖДЕНИЕ, ЕДА - это ДРУГ. ПродуктИвными М-моделями в русской рекламной картине являются М-модели: ЕДА - это ПОБЕДА, ЕДА - это ЗАЩИТНИК, ЕДА - это МАГИЯ. Продуктивными для китайской рекламы, в отличие от русской, являются М-модели: ЕДА - это ВКУС СЕМЬИ, ЕДА - это СПУТНИК;

3. в рамках контрастивного подхода тематической группы «Продукты питания» в русской и китайской национальной картине мира существуют идентичные ценности. Ценностными доминантами «Продукты питания» является стремление к процветанию рода, к цельности и счастью семьи, к богатству и благополучию, к успешной карьере, к здоровью и долголетию, к вечной любви и к дружбе. Можно выделить фрагменты национальной картины мира, которая в обеих культурах характеризуется как гармоничная, коллективная, трудолюбивая.

Перспективы дальнейшего исследования заключаются в более подробном изучении национально-культурных особенностей метафорического представления другой тематической группы в русскоязычных и китайскоязычных материалах.

\section{ЛИТЕРАТУРА}

1. Амири Л.П. Языковая игра в российской и американской рекламе. Автореф. канд. фил...наук. Ростов-на-Дону, 2007. 26 с.

2. Баранов А.Н. Метафорические осмысления справедливости (по материалам центральных печатных изданий) // Коммуникативные исследования. Омск: ОмГУ им. Ф. М. Достоевского, 2015. №1 (3) . С. 7- 31.

3. Баранов Г.С. Модели и метафоры в социологии К. Маркса // Социологические исследования. М: Ис РАН, 1992. № 6. С. 128-142.

4. Бахтин М.М. Творчество Франсуа Рабле и народная культура средневековья и Ренессанса. М.: Худож. лит., 1990. 543 с.

5. Кафтанджиев Христо. Тексты печатной рекламы. Пер. с болгарского под редакцией М. Дымшица / Христо Кафтанджиев. М.: Смысл, 1995. 134 с.

6. Костомаров В.Г., Бурвикова Н.Д. Старые мехи и молодое вино. Из наблюдений над русским словоупотреблением конца XX века. СПб.: Златоуст, 2001.72 с.

7. Курганова Е.Б. Игровой аспект в современном рекламном тексте. Воронеж: ВГУ, 2004. 120 C.

8. Лакофф Дж., Джонсон М. Метафоры, которыми мы живем. // Теория метафоры. М.: Прогресс, 1990. С. 387 - 415.

9. Попова 3.Д., Стернин И.А. Когнитивная лингвистика. М.: АСТ, Восток-Запад, 2007. 315 с.

10. Розенталь Д.Э., Кохтев Н.Н. Язык рекламы текстов. М.: Высшая школа, 1981. 125 с.

11. Серегина Т.К., Титкова Л.М. Реклама в бизнесе. / Под общей ред. д-раэкон. Наук Л.П. Дашкова М.: Информационно - внедренческий центр «Маркетинг», 1995. 112 c.

12. Терских М.В. Реклама как интертекстуальный феномен. Автореф. дис... канд. фи-лол. наук. Омск, 2003. 26 с.

13. Шатин Ю.В. Построение рекламного текста. М.: Бератор-Пресс, 2003. 120 с.

14. Шилихина К.М. Использование метафоры в телевизионной рекламе [Электронный ресурс]. URL: http://lse2010.narod.ru/index/0-230 (дата 0бращения: 25.07.2020).

() Чжу Сянюй (zhuxiangyu050@mail.ru). 